\title{
Sexual Functioning and Its Association with Psychological Symptoms among Doctors Working in a COVID-19 Care Facility: A Cross-sectional Survey
}

\author{
Shankar Kumar ${ }^{1} \oplus$, Archana Gopal ${ }^{2}$, Sushmitha Kota ${ }^{\circledR}$, Anvitha Kayarpady ${ }^{4}$, Prashanth Nagabhushan Rudra ${ }^{5}$
}

\begin{abstract}
Background: Psychological symptoms which are common among frontline healthcare workers (HCWs) can be devastating and can affect sexual functioning of this population.

Aims: The article was to assess sexual functioning among the frontline doctors and to study the association between sexual functioning and psychological symptoms.

Materials and methods: It was a cross-sectional survey conducted among 150 doctors treating COVID-19 patients in a tertiary care teaching hospital. The survey tools included a sociodemographic questionnaire, Depression, Anxiety, and Stress Scale-21 (DASS-21), and Changes in Sexual Functioning Questionnaire (CSFQ) which was sent using a Google Forms link to all participants after informed consent. Chi-square test, $t$-test, Pearson correlation, and multivariate logistic regression were used. $p<0.05$ was considered statistically significant.

Results: Sexual dysfunction was present in 21 (31.62\%) males and 65 (65\%) females. Both males and females with severe stress had lower global sexual functioning scores $(p=0.02,0.02)$. Those with severe stress had reduced sexual frequency, sexual pleasure, and sexual excitement. Global sexual dysfunction was predicted by age $>25$ years in males, working hours $>100$ /month, and severe stress in both males and females. Conclusion: Sexual dysfunction was common in both male and female frontline doctors. Presence of stress, higher age, and greater working hours were associated with poor sexual functioning with decreased sexual desire, sexual pleasure, and sexual arousal.

Keywords: Anxiety, COVID-19, Depression, Healthcare workers, Sexual dysfunction.

Indian Journal of Private Psychiatry (2021): 10.5005/jp-journals-10067-0082
\end{abstract}

\section{INTRODUCTION}

Individuals tend to experience psychological reactions such as anxiety, fear, anger, guilt, depression, and helplessness as a result of the uncertainties associated with COVID-19 infection. ${ }^{1}$ Healthcare workers (HCWs), especially frontline workers are known to be a highrisk vulnerable group for experiencing psychological symptoms. ${ }^{2-4}$ These psychological symptoms can affect sexual functioning of this population in multiple ways. Psychological symptoms can directly affect sexual functioning, primarily decreasing sexual desire. A perspective by Banerjee and Rao on COVID-19 and sexual functioning has described that fear of contagion, need to maintain distancing, travel restrictions, amplification of preexisting marital issues due to increased availability of mutual time all contribute to sexual dysfunction which in fact may affect emotional well-being of an individual and cause turmoil in relationships. ${ }^{5}$

However, there is a significant paucity of literature studying sexual functioning among frontline doctors working for COVID-19 and its association with psychological symptoms. Hence, this study was conducted in this background.

The aims of the study were to assess sexual functioning among the frontline doctors working in COVID-19 care team and study the association between sexual functioning and psychological symptoms.

\section{Materials and Methods}

The study approval was obtained from the Institutional Ethics Committee on July 29,2020, and confidentiality of the participants

\begin{abstract}
${ }^{1-5}$ Department of Psychiatry, Bangalore Medical College and Research Institute, Bengaluru, Karnataka, India

Corresponding Author: Shankar Kumar, Assistant Professor, Department of Psychiatry, Bangalore Medical College and Research Institute, Bengaluru, Karnataka, India, Phone:+91 9844546083, e-mail:shankarkjs@ gmail.com

How to cite this article: Kumar S, Gopal A, Kota S, et al. Sexual Functioning and Its Association with Psychological Symptoms among Doctors Working in a COVID-19 Care Facility: A Cross-sectional Survey. Ind J Priv Psychiatry 2021;15(2):87-91.
\end{abstract}

Source of support: Nil

Conflict of interest: None

was maintained in the study. It was a cross-sectional study conducted among frontline doctors working for a tertiary care COVID-19 treatment facility. Majority of the doctors were postgraduates and senior residents who belong to the age-group of 25-30 years. Snowball technique was used to contact doctors who consented to be a part of the study. The study sample was 150 which was calculated using the formula $4 p q / d^{2}$ where $p$ was assumed to be $30 \%$ based on the previous studies. The study tools were sent using a Google Forms link to all participants after informed consent. We sent the questionnaire to around 256 doctors and 150 responses were obtained. Doctors who were not directly involved in treating COVID-19 patients were excluded. For doctors who had difficulties, consultation with a psychiatrist was suggested.

(O) The Author(s). 2021 Open Access This article is distributed under the terms of the Creative Commons Attribution 4.0 International License (https://creativecommons. org/licenses/by-nc/4.0/), which permits unrestricted use, distribution, and non-commercial reproduction in any medium, provided you give appropriate credit to the original author(s) and the source, provide a link to the Creative Commons license, and indicate if changes were made. The Creative Commons Public Domain Dedication waiver (http://creativecommons.org/publicdomain/zero/1.0/) applies to the data made available in this article, unless otherwise stated. 
The tools used were as follows:

- Sociodemographic questionnaire containing the past history of psychiatric and medical illness, substance use, and family history of psychiatric illness.

- DASS-21 which is a self-report scale with 21 items designed to measure depressive symptoms, anxiety symptoms, and stress with seven items per scale. It has excellent Cronbach's alpha values of $0.81,0.89$, and 0.78 for subscales of depression, anxiety, and stress, respectively. ${ }^{6}$

- CSFQ is a self-report scale with 14 items with separate scores of 5 subscales (sexual desire/frequency, sexual desire/interest, sexual pleasure, sexual arousal/excitement, and sexual orgasm). It is a reliable and valid measure of sexual functioning useful in both research and clinical settings. ${ }^{7}$

\section{Statistical Analysis}

Statistical analysis was done using SPSS V20. Fisher's exact test was used to measure the association of sexual functioning with underlying vulnerabilities. A $t$-test was used to measure differences between psychological symptoms and subscale scores of CSFQ. Pearson correlation was used to assess the correlation of psychological symptoms with sexual functioning. Univariate and multivariate logistic regression was done to predict odds of sexual dysfunction using variables with a significant correlation. Significance was assumed when $p \leq 0.05$.

\section{Results}

Table 1 shows that among 150 participants, 53 (35.33\%) were male and 97 (52.67\%) were female. Fifty-eight (38.67\%) doctors were married and 92 (61.33\%) doctors were staying without family in our study. The mean working hours of doctors per month was $121.56 \pm 51.20$ hours. Fourteen (9.33\%) doctors had medical comorbidities and 11 (7.33\%) had psychiatric illness in the past. Fifteen (10\%) gave the history of substance use and 15 (10\%) doctors had a family history of psychiatric illness.

Sexual dysfunction was present in 21 (31.62\%) males and 65 (65\%) females.

Table 2 shows that males with sexual dysfunction had higher scores on stress $(10.05 \pm 2.35)$ when compared to those without sexual dysfunction $(8.5 \pm 2.25)$. There were no significant differences in anxiety and depression scores ( $p$-values: 0.1 and 0.5 , respectively).

Table 3 shows that females with sexual dysfunction had higher scores on stress $(11.32 \pm 2.54)$ when compared to those without sexual dysfunction $(9.68 \pm 1.25)$. There were no significant differences in anxiety and depression scores among females with and without sexual dysfunction ( $p$-values: 0.4 and 0.36 , respectively).

Table 4 shows that there is a significant correlation of stress with global sexual functioning scores among males $(r=0.43$, p-value: 0.03 ).

Table 5 shows that males with severe stress had decreased sexual desire/frequency, sexual pleasure, sexual arousal/ excitement, and global scores ( $p$-value: $0.002,0.006,0.001$, and 0.002 , respectively).

Table 6 shows that there was a significant correlation between stress and global sexual dysfunction among females ( $r$-value: 0.46 ; p-value: 0.02).

Table 7 shows that females with severe stress had increased sexual desire/frequency, sexual pleasure, sexual arousal/excitement, sexual orgasm, and global scores when compared to those without
Table 1: Sociodemographic characteristics of population

\begin{tabular}{ll}
\hline Characteristics & \multicolumn{1}{c}{ Values } \\
\hline Age & (Mean \pm SD) \\
Marital status & \\
- Unmarried & $N=121(80.67 \%)$ \\
- Married & $N=29(19.33 \%)$ \\
Current living status & \\
- With family & $N=58(38.66 \%)$ \\
- Outside the family & $N=92(61.33 \%)$ \\
Working hours per month & $($ Mean \pm SD) \\
Past history of medical illness & $121.56 \pm 51.20$ hours \\
- Nil & \\
- Yes & $N=139(92.67 \%)$ \\
Past history of psychiatric illness & $N=11(7.33 \%)$ \\
- Nil & \\
- Yes & $N=139(92.67 \%)$ \\
- Depression & $N=11(7.33 \%)$ \\
- Anxiety spectrum & $N=4(2.67 \%)$ \\
Family history of psychiatric illness & $N=7(4.67 \%)$ \\
- Nil & $N=135(90 \%)$ \\
- Yes & $N=15(10 \%)$ \\
- Psychosis & $N=4(2.67 \%)$ \\
- Anxiety & $N=3(2 \%)$ \\
- Depression & $N=3(2 \%)$ \\
- Bipolar & $N=3(2 \%)$ \\
- Unspecified & $N=1(0.67 \%)$ \\
& $N=1(0.67 \%)$ \\
\hline
\end{tabular}

Table 2: Differences in psychological symptoms among those with and without sexual dysfunction in males

\begin{tabular}{lcccc}
\hline & $\begin{array}{c}\text { No sexual } \\
\text { dysfunction } \\
(N=32)\end{array}$ & $\begin{array}{c}\text { Sexual } \\
\text { dysfunction } \\
\text { present }(N=21)\end{array}$ & t value & $p$ value \\
\hline Stress & $8.5 \pm 2.25$ & $10.05 \pm 2.35$ & 2.41 & $0.01^{\mathrm{a}}$ \\
Anxiety & $6.6 \pm 1.95$ & $7.42 \pm 1.4$ & 1.66 & 0.1 \\
Depression & $6.3 \pm 72.19$ & $7.1 \pm 2.24$ & 0.59 & 0.5 \\
\hline
\end{tabular}

${ }^{a}$ Represents significant association $(p \leq 0.05)$

Table 3: Differences in psychological symptoms among those with and without sexual dysfunction in females

\begin{tabular}{lcccc}
\hline & $\begin{array}{c}\text { Sexual } \\
\text { dysfunction } \\
\text { present }(N=65)\end{array}$ & $\begin{array}{c}\text { No sexual } \\
\text { dysfunction } \\
(N=35)\end{array}$ & tvalue & $p$ value \\
\hline Stress & $11.32 \pm 2.54$ & $9.68 \pm 1.25$ & 3.39 & $0.03^{\mathrm{a}}$ \\
Anxiety & $9.78 \pm 2.32$ & $9.22 \pm 1.3$ & 1.67 & 0.4 \\
Depression & $9.69 \pm 3.11$ & $9.1 \pm 1.26$ & 1.89 & 0.36 \\
\hline
\end{tabular}

${ }^{a}$ Represents significant association $(p \leq 0.05)$

stress. However, the scores among those with severe stress also fell in the sexual dysfunction range when cutoffs mentioned in the scale were taken into account ( $p$-value: $0.002,0.001,0.001,0.05$, 0.002 , respectively).

Table 8 shows that higher odds of global sexual dysfunction in males were predicted by age $>25$ years $(O R=2.23)$, working 
Table 4: Pearson correlation between psychological symptoms and global sexual functioning scores in males

\begin{tabular}{lcc}
\hline & rvalue $^{b}$ & pvalue \\
\hline Stress & 0.43 & $0.03^{\mathrm{a}}$ \\
Anxiety & 0.11 & 0.12 \\
Depression & 0.16 & 0.10 \\
\hline
\end{tabular}

${ }^{\mathrm{a}}$ Represents significant association $(p \leq 0.05)$; ${ }^{\mathrm{b}}$ Represents $r=$ Pearson correlation coefficient

Table 5: Subscale score differences in CSFQ among those with and without severe stress in males

\begin{tabular}{lcccc}
\hline & $\begin{array}{c}\text { Without } \\
\text { severe stress } \\
(N=53)\end{array}$ & $\begin{array}{c}\text { With } \\
\text { severe stress } \\
(N=5)\end{array}$ & tvalue & p value \\
\hline $\begin{array}{l}\text { Subscales of CSFQ } \\
\begin{array}{l}\text { Sexual desire/ } \\
\text { frequency }\end{array}\end{array}$ & $7.53 \pm 0.48$ & $6.66 \pm 0.13$ & 4.00 & $0.002^{\mathrm{a}}$ \\
$\begin{array}{l}\text { Sexual desire/interest } \\
\text { Sexual pleasure }\end{array}$ & $12.93 \pm 3.41$ & $11.2 \pm 2.12$ & 1.1 & 0.2 \\
$\begin{array}{l}\text { Sexual arousal/ } \\
\text { excitement }\end{array}$ & $9.89 \pm 0.31$ & $10.8 \pm 1.09$ & 4.66 & $0.001^{\mathrm{a}}$ \\
$\begin{array}{l}\text { Sexual orgasm/ } \\
\text { completion }\end{array}$ & $10.04 \pm 1.49$ & $10.12 \pm 1.21$ & 0.12 & 0.9 \\
Global scores & $53.54 \pm 4.77$ & $46.6 \pm 4.43$ & 3.12 & $0.002^{\mathrm{a}}$ \\
\hline
\end{tabular}

Represents significant association $(p \leq 0.05)$

Table 6: Pearson correlation between psychological symptoms and global sexual functioning scores in females

\begin{tabular}{lcc}
\hline & rvalue $^{b}$ & $p$ value \\
\hline Stress & 0.46 & $0.02^{\mathrm{a}}$ \\
Anxiety & 0.21 & 0.13 \\
Depression & 0.18 & 0.15 \\
\hline
\end{tabular}

Represents significant association $(p \leq 0.05)$; ${ }^{\text {b }}$ Represents $r=$ Pearson correlation coefficient

Table 7: Subscale score differences in CSFQ among those with and without severe stress in females

\begin{tabular}{lcccc}
\hline & $\begin{array}{c}\text { Without } \\
\text { severe stress } \\
(N=91)\end{array}$ & $\begin{array}{c}\text { With } \\
\text { severe stress } \\
(N=6)\end{array}$ & tvalue & $p$ value \\
\hline $\begin{array}{l}\text { Subscales of CSFQ } \\
\text { Sexual desire/ } \\
\text { frequency }\end{array}$ & $3.55 \pm 0.52$ & $4.5 \pm .23$ & 4.42 & $0.001^{\mathrm{a}}$ \\
$\begin{array}{l}\text { Sexual desire/ } \\
\text { interest }\end{array}$ & $5.61 \pm 1.25$ & $6.16 \pm 1.1$ & 1.05 & 0.2 \\
$\begin{array}{l}\text { Sexual pleasure } \\
\text { Sexual arousal/ } \\
\text { excitement }\end{array}$ & $1.82 \pm 0.29$ & $2.16 \pm 0.12$ & 8.61 & $0.001^{\mathrm{a}}$ \\
$\begin{array}{l}\text { Sexual orgasm/ } \\
\text { completion }\end{array}$ & $5.26 \pm 1.55$ & $6.5 \pm 1.44$ & 1.91 & $0.05^{\mathrm{a}}$ \\
Global scores & $26.76 \pm 3.57$ & $22.16 \pm 2.65$ & 3.09 & $0.002^{\mathrm{a}}$ \\
\hline
\end{tabular}

Represents significant association $(p \leq 0.05)$

hours $>100$ hours/month ( $O R=2.92)$, presence of severe stress $(O R=4.48)$, and decreased sexual excitement $(O R=4.57)$ (overall Chi-square: 22.08 , degree of freedom: 4 , and $p$-value $<0.001$ )

Table 9 shows that higher odds of global sexual dysfunction in females were predicted by working hours $>100$ hours/month $(O R=3.47)$, presence of severe stress $(O R=3.97)$, and decreased sexual pleasure $(O R=3.38)$ (overall Chi-square: 19.54 , degree of freedom: 4 , and $p$-value $<0.001)$.

\section{Discussion}

\section{Sociodemographic Characteristics of the Population}

Most of the sample population were young adults, unmarried, and living outside the family. This could be because of the study sample predominantly comprised of postgraduates and senior residents who are aged between 25 and 30 years. The past history of psychiatric illness was present in $7.33 \%$ of the study sample which is representative of existing literature which reveals one in seven Indians to be affected by mental disorders. ${ }^{8}$

\section{Psychological Symptoms and Sexual Dysfunction}

Stress scores were higher among those with sexual dysfunction in both genders. Also, stress had a positive correlation with global sexual functioning among males and females. Stress associated with intimacy during COVID-19 among frontline doctors may arise from multiple sources including concerns of transmission of the infection during sex, infecting the partner, quarantine measures advocated for the frontline doctors, relational issues arising from periods of prolonged isolation from the partner. ${ }^{5}$

A review by Bancroft mentions that role of situational impediments that are associated with a lack of opportunities for intimacy along with psychological factors is known to affect sexual functioning in both genders which could be linked to hormonal and neurological factors. ${ }^{9}$

The findings of our study are in concordance with the above review. Though scores on individual domains were higher among those with stress in females, it still fell within the sexual dysfunction range on CSFQ. Also, global sexual dysfunction scores were higher among those with stress in females which is in line with existing literature.

\section{Factors Predicting Sexual Dysfunction}

In males, sexual dysfunction was predicted by higher age, greater working hours per month, and higher stress scores. In females, sexual dysfunction was predicted by greater working hours per month and higher stress scores. Sexual functioning is known to decline with age. A review by O'Sullivan states that age is clearly linked to onset of sexual dysfunctions with young adults experiencing dysfunctions as they age. ${ }^{10}$

A review by Gupta discusses the high prevalence of mental health issues among HCWs related to occupational stress such as long working hours, limited resources, and changing duties. This in turn could be associated with high burnout and stress and may affect sexual functioning. ${ }^{11}$

\section{Strengths and Limitations of the Study}

This was one among the first studies in our knowledge to study sexual functioning among frontline doctors working for COVID-19. We also assessed various domains of sexual dysfunction and its association with stress along with factors predicting sexual dysfunction in this population.

There were also several limitations in our study. It was a simple cross-sectional survey with limitations of a survey design. There was a presence of significant confounding factors which could have influenced outcomes. We did not assess various sexual practices of the study population. Majority of the population was unmarried and living outside the family which could have affected outcomes. Sexual functioning changes over time based on environmental/situational 
Table 8: Univariate and multivariate logistic regression to predict sexual dysfunction in males

\begin{tabular}{|c|c|c|c|c|c|}
\hline & \multicolumn{2}{|c|}{ Univariate analysis } & \multicolumn{2}{|c|}{ Multivariate analysis } & \multirow[b]{2}{*}{ Overall model fit } \\
\hline & $O R^{b}$ & pvalue & OR & pvalue & \\
\hline Age $>25$ years & 3.14 & $0.03^{a}$ & 2.23 & $0.03^{a}$ & \multirow{8}{*}{$\begin{array}{l}\text { Chi-square }=22.08 \\
\mathrm{df}=4 \\
p<0.001^{\mathrm{a}}\end{array}$} \\
\hline Married status & 1.58 & 0.37 & - & - & \\
\hline Working hours $>100 /$ month & 4.56 & $0.01^{\mathrm{a}}$ & 2.92 & $0.008^{\mathrm{a}}$ & \\
\hline $\begin{array}{l}\text { Duration of experience } \\
<1 \text { year }\end{array}$ & 1.12 & 0.97 & - & - & \\
\hline Severe stress & 5.27 & $0.001^{\mathrm{a}}$ & 4.48 & $0.003^{\mathrm{a}}$ & \\
\hline Sexual frequency & 2.23 & 0.72 & - & - & \\
\hline Sexual pleasure & 4.46 & $0.03^{\mathrm{a}}$ & 2.27 & 0.08 & \\
\hline Sexual excitement & 6.67 & $0.001^{\mathrm{a}}$ & 4.57 & $0.001^{\mathrm{a}}$ & \\
\hline
\end{tabular}

${ }^{\mathrm{a}}$ Represents significant association $(p \leq 0.05) ;{ }^{\mathrm{b}} \mathrm{OR}=$ Odds ratio

Table 9: Univariate and multivariate logistic regression to predict sexual dysfunction in females

\begin{tabular}{|c|c|c|c|c|c|}
\hline & \multicolumn{2}{|c|}{ Univariate analysis } & \multicolumn{2}{|c|}{ Multivariate analysis } & \multirow[b]{2}{*}{ Overall model fit } \\
\hline & $O R^{b}$ & $p$ value & $O R$ & $p$ value & \\
\hline Age $>25$ years & 1.35 & 0.71 & - & - & \multirow{9}{*}{$\begin{array}{l}\text { Chi-square = 19.54, } \\
\mathrm{df}=4, \\
p<0.001^{\text {a }}\end{array}$} \\
\hline Married status & 1.09 & 0.87 & - & - & \\
\hline Working hours $>100 /$ month & 5.65 & $0.01^{a}$ & 3.47 & $0.03^{a}$ & \\
\hline Duration of experience $<1$ year & 2.33 & 0.19 & - & - & \\
\hline Severe stress & 6.86 & $0.001^{\mathrm{a}}$ & 3.97 & $0.03^{\mathrm{a}}$ & \\
\hline Sexual frequency & 3.44 & $0.05^{\mathrm{a}}$ & 1.97 & 0.09 & \\
\hline Sexual pleasure & 4.99 & $0.02^{\mathrm{a}}$ & 3.38 & $0.009^{\mathrm{a}}$ & \\
\hline Sexual excitement & 2.33 & 0.09 & 1.07 & 0.12 & \\
\hline Orgasm/completion & 1.98 & 0.16 & - & - & \\
\hline
\end{tabular}

${ }^{\mathrm{a}}$ Represents significant association $(p \leq 0.05) ;{ }^{\mathrm{b}} \mathrm{OR}=$ Odds ratio

factors which were not studied. Effect of relational variables on sexual functioning was not studied. Though psychological symptoms were assessed, the presence of psychiatric diagnosis could have been studied. Coping can mediate the relationship between stress and sexual functioning which was not studied.

Nevertheless, this was one of the first studies in our knowledge to assess the presence of sexual dysfunction and its domains and relationship with psychological factors among doctors working for COVID-19 pandemic. Though we could establish a relationship between sexual dysfunction and stress, there is a need to assess factors contributing to stress and coping, its impact on relationships, functioning, and interventions which could benefit this population.

\section{Conclusion}

Sexual dysfunction was common in both male and female frontline doctors working in a COVID-19 setup. Stress was positively correlated with sexual functioning with decreased sexual desire, sexual pleasure, and sexual arousal. Those with age $>25$ years, working $>100$ hours/month, and severe stress had a higher odds of having global sexual dysfunction.

\section{ORCID}

Shankar Kumar (1) https://orcid.org/0000-0002-8002-4576 Sushmitha Kota $\odot$ https://orcid.org/0000-0003-0668-4944

\section{References}

1. Chew QH, Wei KC, Vasoo S, et al. Narrative synthesis of psychological and coping responses towards emerging infectious disease outbreaks in the general population: practical considerations for the COVID-19 pandemic. Singapore Med J 2020;61(7):350-356. DOI: 10.11622/smedj.2020046.

2. Tham KY, Tan YH, Loh OH, et al. Psychological morbidity among emergency department doctors and nurses after the SARS outbreak. Ann Acad Med Singap. 2004;33(5 Suppl):S78-S79. DOI: $10.1177 / 102490790501200404$.

3. Chua SE, Cheung V, Cheung C, et al. Psychological effects of the SARS outbreak in Hong Kong on high-risk health care workers. Can J Psychiatry 2004;49(6):391-393. DOI: 10.1177/070674370404900609.

4. Poon E, Liu KS, Cheong DL, et al. Impact of severe respiratory syndrome on anxiety levels of front-line health care workers. Hong Kong Med J 2004;10(5):325-330. PMID: 15479961.

5. Banerjee D, Rao TS. Sexuality, sexual well being, and intimacy during COVID-19 pandemic: an advocacy perspective. Indian J Psychiatry 2020;62(4):418-426. DOI: 10.4103/psychiatry. IndianJPsychiatry_484_20.

6. Gloster AT, Rhoades HM, Novy D, et al. Psychometric properties of the depression anxiety and stress scale-21 in older primary care patients. J Affect Disord 2008;110(3):248-259. DOI:10.1016/j. jad.2008.01.023.

7. Keller A, McGarvey EL, Clayton AH. Reliability and construct validity of the Changes in Sexual Functioning Questionnaire short-form (CSFQ-14). J Sex Marital Ther 2006;32(1):43-52. DOI: $10.1080 / 00926230500232909$. 
8. India State-Level Disease Burden Initiative Mental Disorders Collaborators. The burden of mental disorders across the states of India: The Global Burden of Disease Study 1990-2017. Lancet Psychiatry 2020;7(2):148-161. DOI: 10.1016/S2215-0366(19)30475-4.

9. Bancroft J. Impact of environment, stress, occupational, and other hazards on sexuality and sexual behavior. Environ Health Perspect 1993;101:101-107. DOI: 10.2307/3431382.
10. O'Sullivan LF. Sexual function and problems with adolescents and young adults. Curr Sex Health Rep 2015;7:12-18. DOI: 10.1007/s11930014-0035-5.

11. Gupta S, Sahoo S. Pandemic and mental health of the frontline healthcare workers: a review and implications in the Indian context amidst COVID-19. Gen Psychiatr 2020;33(5):e100284. DOI: 10.1136/ gpsych-2020-100284. 